\title{
Gamma Radiation Induce Inflammasome Signaling and Pyroptosis in Microvascular Endothelial Cells
}

\author{
Alhaji Osman Smith ${ }^{1,2}$ \\ Wen Ju ${ }^{1-3}$ \\ Seyram Yao Adzraku',2 \\ Lu wenyi ${ }^{1,2}$ \\ Chen Yuting ${ }^{1,2}$ \\ Jianlin Qiao ${ }^{1-3}$ \\ Kailin Xu $\mathbb{D}^{1-3}$ \\ Lingyu Zeng ${ }^{\mathrm{I}-3}$
}

'Department of Blood Diseases Institute, Xuzhou Medical University, Xuzhou City, 221002, Jiangsu Province, People's Republic of China; ${ }^{2}$ Department of Key Laboratory of the Bone Marrow Stem Cell, Xuzhou Medical University, Xuzhou City, 221002, Jiangsu Province, People's Republic of China; ${ }^{3}$ Department of Hematology, The Affiliated Hospital of Xuzhou Medical University, Xuzhou City, 221002, Jiangsu Province, People's Republic of China
Correspondence: Kailin Xu; Lingyu Zeng Tel +86I5I62I66I66; +86I3685I82368 Email lihmd@।63.com; zengly2000@I63.com
Introduction: The extend to the clinical benefit of radiation therapy is the inability to eliminate only cancer cells and destroy normal cells such as microvascular endothelial in the vascular niche and turn induced-inflammasome signaling and cell death. These unfortunate injuries generated by ionizing radiation alter the therapeutic window and result in the reoccurrence of the malignancy. Therefore, we engaged in vitro studies by demonstrating radiation-induced inflammasome and cell death in endothelial cells.

Methods: The microvascular endothelial cells were cultured in a sterile dish, then kept in a humidifier of $5 \%$ at $37^{\circ} \mathrm{C}$ for 12 hours/more to attain confluence, and exposed at a dose of $1.8 \mathrm{~Gy} / \mathrm{min}$ achieve the coveted amounts except for the control. The cells were harvested 24 hours post-irradiation.

Results: Our findings indicate that gamma radiation activates the NOD-like receptor (NLR) family of NLRP1 and NLRP3 complex in microvascular endothelial cells. These complexes activate the inactive precursor of caspase-1, which cleaved to bioactive caspase -1 and enhances the production of pro-inflammatory cytokines of interleukin- $1 \beta$ and interleukin-18 that induce the dependent pyroptotic, which results in the production of chemokines, tumor necrosis factor-alpha (TNF- $\alpha$ ), and high-mobility group protein-1 (HMGB-1). We also discovered the radiation could directly prompt caspase -1 , which auto-cleaved to activate gasdermin D to potentiate pyroptosis independently.

Discussion: Overall, these findings suggested that reducing the unfavorable effect of radiation injuries could be challenging since gamma radiation induces the microvascular endothelial cells to cell death and activates the inflammasome signaling via different pathways.

Keywords: gamma radiation, microvascular endothelial cells, ECs, NOD-like receptor, NLR, inflammasome, pyroptosis

\section{Introduction}

Radiation therapy is emerging as therapeutic measures to treat malignancies such as glioblastoma, advanced prostate cancer, leukemia, lymphoma, and multiple myeloma. More significantly, in cases not responding to chemotherapeutic agents to destroy tumor cells and shrink the cancers. Thus, in that process, it activates and damages rapidly dividing cells and quiescent cells such as microvascular endothelial cells, which have the capability of self-renewal, proliferation, and differentiation. ${ }^{1-3}$ However, the slight clinical benefit of radiation is the inability to destroy only cancer cells and damage the intact DNA. Its repair mechanism, in turn, induces an inflammasome $e^{4,5}$ Activation of these intracellular proteins of NOD-like receptor (NLR) of (NLRP1/ NLRP3) due to microbes or sterile processes such as ionizing radiation forms 
a multi-protein complex called the inflammasome. Those inflammasome complexes can either directly lead to activation of the caspase-1, a protease required for interleukin 1-beta (IL-1 $\beta$ ) and interleukin -18 (IL-18) maturation and secretion, or indirectly recruits the inflammasome caspase recruitment domain (ASC protein), which facilitates the binding and oligomerization of caspase-1 auto-cleavage and activation that results in processing inactive proinflammatory cytokines to their bio-active forms interleukins' (IL-1 $\beta$, IL-18) ${ }^{6-8}$ The activation of the caspase-1 also derives cleavage the auto-inhibitory domain from Gasdermin-D, a liberation of the amino-terminal poreforming domain of Gasdermin-D to translocate to the plasma membrane and oligomerize, forming pores that initiate hypotonic cellular swelling and lysis. All these processes occur as a result of prolonged activation of the inflammasome signaling that leads to caspase-1- mediated cell death termed pyroptosis/apoptosis that mediates the release of other inflammatory mediators such as high-mobility group protein-1 (HMGB-1) and tumor necrosis factor-alpha (TNFa). ${ }^{9-12}$ Despite the role of NLR-dependent events in innate immune response, the part of the inflammasome in microvascular endothelial cells due to ionizing radiation has yet to be studied. The microvascular endothelial cells are located in the smallest vessels and have a significant role in vessel homeostasis, and their dysfunctions may lead to many varieties of disease. Besides, they are the primary responders to inflammatory injuries such as radiation, whereby they grow to maintain the integrity of the vessel. Despite the abovehypothesized explanation, the exact mechanism by which the microvascular endothelial cells result from radiation injury remains unclear. ${ }^{13-15}$ Characterization of the altered microvascular endothelial cells gene expression in response to radiation will help hypothesize the endothelial cell's mechanisms that regulate regeneration and develop therapeutic strategies to reduce the long-term complication of ionizing radiation exposure. In this research, we evaluate the effect of ionizing radiation in the microvascular endothelial cells concerning inflammasome and pyroptosis after post-ionizing radiation.

\section{Methods and Materials}

\section{Cell Preparation}

The microvascular brain endothelial cells (ECs) bought from the American Type Culture Collection (Manassas, VA, USA) were cultured in a growth medium Dulbecco's Modified Eagle Medium (DMEM) containing 10\% fetal bovine serum (FBS) and $500 \mu \mathrm{L}$ of penicillin $(10,000$ uints $/ \mathrm{mL}) /$ streptomycin 10,000 $\mathrm{g} / \mathrm{mL}$ (both from Gibco; Thermo Fisher Scientific Inc., Waltham, MA, USA). The resuspended cells are store in a humidified $5 \% \mathrm{CO}_{2}, 37^{\circ} \mathrm{C}$ incubator.

\section{Gamma-Irradiation}

The microvascular endothelial cells were sub-cultured at a density of $1.50 \times 10^{6}$ cells $/ \mathrm{mL}$ in a sterile dish of at least three experimental repeats, then stored in a humidifier of $5 \%$ at $37^{\circ} \mathrm{C}$ for at least 12 hours/more into different grouped for radiation exposure. When the adherent monolayer cells attained $60-70 \%$ confluence, then exposed at a dose of $1.8 \mathrm{~Gy} / \mathrm{min}$ according to the manufacturer's instruction (Gamma-service Medical, GmbH, Leipzig Germany) to achieve the coveted desired amounts $(2,2.5,5,7.5$ and $10 \mathrm{~Gy}$, respectively) except for the control, but placed under the same experimental conditions. Cells were harvest after 24 hours post-irradiation for further analysis.

\section{Determination of Cell Death in Irradiated Microvascular Endothelial Cells}

Measuring pyroptosis/apoptosis of the microvascular endothelial cells, about 10,000 cells $/ \mathrm{mL}$ were inoculated into a sterile dish and store in a humidified $5 \% \mathrm{CO}_{2}$, at $37^{\circ}$ $\mathrm{C}$ incubate for at least $12 \mathrm{~h}$ hours or more to attain a confluence of $60-70 \%$ of the monolayer adherent cells, then exposed to different groups of gamma radiation. Cells were cultivated after 24 hours of irradiation by $0.25 \%$ trypsinization, followed by centrifugation at $300 \mathrm{~g}$ for 5 minutes at room temperature. Next, cells washed with $1 \mathrm{x}$ phosphatebuffered saline (PBS) containing $1 \%$ bovine serum albumin (BSA), then resuspended with 100ul of $1 \mathrm{x}$ apoptotic staining buffer followed by the addition of FAM-FLICA working solution $\quad\left(\right.$ FAM-FLICA $^{\circledR} \quad$ Caspase assay \#97, Immunochemistry Technologies, LCC, and Bloomington, MN, USA) and incubated at room temperature (RT) for 60 minutes with intermittent mixing. Cells were washed twice with the washing buffer (1\%PBS/BSA), centrifuged, and acquired by flow cytometry within 24 hours. The data obtained were analyzed by Flow Jo software version 7.6.2.

\section{Deduction of Interleukin-I Beta (IL-I $\beta$ ) Expression by Flow Cytometry Analysis in Irradiated Microvascular Endothelial Cells}

To examine the surface marker of IL- $1 \beta$ expression in microvascular endothelial cells, approximately $1.5 \times 10^{4}$ cells $/ \mathrm{mL}$ 
Table I Real-Time Quantitative PCR Primer Sequences

\begin{tabular}{|c|c|c|}
\hline \multirow[t]{2}{*}{ Target Genes } & \multicolumn{2}{|l|}{ Primer Sequences } \\
\hline & Forward 5' $\rightarrow$ 3' & Reverse $3^{\prime} \rightarrow 5^{\prime}$ \\
\hline NIrp I & GCATTAAGTTCTGCTGTCACG & CTCAGGGTCGTACAAAGACTGT \\
\hline TNF- $\alpha$ & AGTCCGGGCAGGTCTACTTT & TTGGACCCTGAGCCATAATC \\
\hline IL-18 & GCCTCAAACCTTCCAAATCA & GTGAAGTCGGCCAAAGTTGT \\
\hline IL-I $\beta$ & TGCCACCTTTTGACAGTGATG & TGATGTGCTGCTGCGAGATT \\
\hline hmgb I & CTGGCTGGAGAGTAATGTTACAGA & TCATAACGAGCCTTGTCAGCC \\
\hline CASPASE I & ATCTTTCTCCGAGGGTTGG & AAGTCTTGTGCTCTGGGCAG \\
\hline BETA ACTIN & ATGTGGATCAGCAAGCAGGA & AAGGGTGTAAAACGCAGCTCA \\
\hline GAPDH & CATGGCCTTCCGTGTTCCTA & GCGGCACGTCAGATCCA \\
\hline
\end{tabular}

were inoculated into a sterile dish, then stored in a humidifier at $5 \% \mathrm{CO}_{2}$, at $37^{\circ} \mathrm{C}$ incubator at 24 hours or more. The cells are then exposed to a different group of ionizing radiation. Cells were removed after 24 hours of post-irradiation by $0.25 \%$ trypsinization and centrifuge at $200 \mathrm{~g}$ for 5 minutes at RT. All samples were washed twice with PBS containing $1 \%$ BSA and permeabilized with $90 \%$ methanol at $-20^{\circ}$ $\mathrm{C}$ for 1 hour. The cells were washed with cold 1\% PBS/ BSA (3x) solution and resuspended with cold 1\%BSA/PBS followed the addition of the antibodies primary and secondary [rabbit monoclonal IL-1 $\beta$ (D6D6T) antibody (cat no. 31202), 1:10 dilution and Alexa Fluor ${ }^{\circledR} 647$ (cat no. 4414), 1:500 dilution] according to recommended dilution of the manufacturer's instruction. All samples were stored at $4^{\circ} \mathrm{C}$ for 1 hour, washed twice cold $1 \%$ PBS/BSA buffer, centrifuged at $300 \mathrm{~g}$ for 5 minutes at $4^{\circ} \mathrm{C}$, and the cells were then resuspended in $200 \mu \mathrm{L}$ of cold PBS solution, followed by the acquisition of data by flow cytometry within 24 hours. All samples were repeated at least three times, and the data were acquired according to the manufacturer's protocols, then analyzed by Flow Jo software version 7.6.2.

\section{Quantitative Real-Time Polymerase Chain Reaction (qRT-PCR)}

The total RNA extracted from monolayer the adherent microvascular endothelial cells after 24 hours postirradiation using Trizol reagent (Life science, Technologies, Carlsbad, CA, USA). The purity of the total isolated RNA was determined by NanoDrop spectrophotometer with an OD ratio of 260/280 between 1.8 and 2.2 attained, and the samples stored at -80 degrees. One microgram $(1 \mu \mathrm{g})$ of the total isolated RNA was treated with DNase I (Beyotime, Biotechnology China) before clonal DNA synthesis following the manufacturer's instruction. The purified RNA was then converted to
cDNA by primer Script reverse transcriptase master mix (Takara Biotechnology, Dalian, China). QRT-PCR performed in 96 -well plate using the Light Cycler ${ }^{\circledR} 480$ software release 1.5.0 SP4 with 50ng first-strand cDNA solution combined with SYBR Green I Master mix in a final volume of 20ul. The QRT-PCR program was comprised of pre-denaturation at $95^{\circ} \mathrm{C}$ for 10 minutes, 40 cycles at $95^{\circ} \mathrm{C}$ for 30 seconds, $60^{\circ} \mathrm{C}$ for 15 seconds, and $60^{\circ} \mathrm{C}$ for 15 seconds. The primers used in this study listed in Table 1, and all samples ran in triplicate and underwent 40 amplification cycles. The basal line CT values were obtained under the manufacturer's protocols. We evaluate the expression of the genes of interest using two reference genes glyceraldehyde-3-phosphate Dehydrogenase (GAPDH) and Beta-actin).

\section{Western Blot Analysis}

For immuno-blotting analysis, the adherent monolayer endothelial cells were washed with ice-cold PBS buffer twice, and the appropriate cell lysis (Herpes-Chaps) buffer containing a cocktail of proteases inhibitors was poured into the dish and incubated on ice for 5 minutes, followed by gentle scraping of the adherent cells, then transfer into sterile $1.5 \mathrm{~mL}$ EP tubes. The cell lysate was further incubated on ice for 10 minutes with intermittent agitation and then centrifuged at $15,000 \mathrm{rpm}$ for 30 minutes at $4^{\circ} \mathrm{C}$. The protein concentration was determined with a BCA protein concentration assay (Beyotime, Biotechnology, China). An equal amount of protein $(20 \mu \mathrm{g})$ separated on $6-15 \%$ SDS-PAGE gels electrophoretically and transferred to PVDF membranes for 1 hour for proteins less than 100kda and 90 minutes for proteins above $100 \mathrm{kda}$ at a constant voltage of $100 \mathrm{~V}$ and $120 \mathrm{~V}$, respectively. The membranes were blocked with 5\% non-fat milk for 1 hour at RT, then incubated with the primary antibodies based on the recommended dilutions of 
the antibody $(1: 1000)$ overnight at $4^{\circ} \mathrm{C}$, then HRP-linked secondary antibodies (rabbit: 1:1000) for 1 hour at RT. According to the manufacturer's instruction, autoradiograph, and recorded on films, immunoblots were detected using an ECL prime Western blotting Detection Reagents (GE, Healthcare Life Sciences, Little Chalfont, and the UK). Bands intensities quantified by Image $\mathrm{J}$ software version 1.45S (National Institute of Health, Bethesda, MD, USA). Then related proteins expression of the targeted proteins were normalized to that of Beta-actin proteins.

\section{Immunofluorescence}

The microvascular endothelial cells $(10,000$ cells $)$ were plated in coverslips and incubated for $24-48 \mathrm{hrs}$ to form the confluence of $60-70 \%$ in a humidified $5 \% \mathrm{CO}_{2} 37^{\circ}$ $\mathrm{C}$. The adherent monolayer microvascular endothelial cells were exposed to radiation, as described above. After 24 hours post-irradiation, Microvascular endothelial cells were washed with $1 \mathrm{X}$ PBS, fixed with $90 \%$ methanol for 20 minutes at room temperature. The cells were washed three times and block with $1 \% \mathrm{BSA} / \mathrm{PBS}$ at room temperature for 1 hour. The microvascular endothelial cells were then incubated with an anti-caspase 1 antibody (1:100 dilution) at $37^{\circ} \mathrm{C}$ for 1 hour. The cells were washed three times with PBS and incubated with Alexa Fluor ${ }^{\circledR}$ 594 (1:500 dilution) at room temperature for 1 hour. The adherence cells were washed with PBS gently for 3 minutes twice and counterstained with DAPI for 5 minutes at $37^{\circ} \mathrm{C}$. The cells were washed with PBS, and imaging acquired using Nikon confocal microscopy. The data analyzed by Image J software.

\section{Antibodies}

Polyclonal NALP1 antibody (cat no. 4990), polyclonal TNF- $\alpha$ antibody (pro and cleaved, cat no. 3707), rabbit monoclonal IL-1 $\beta$ (D6D6T) antibody (pro and cleaved, cat no. 31202), rabbit monoclonal HMBG1 (D3E5) antibody (cat no. 6893), Alexa Fluor ${ }^{\circledR} 647$ (cat no. 4414), and antirabbit IgG HRP-linked antibody (cat no. 7074) were purchased from Cell Signaling Technology (Danvers, MA). In addition, rabbit polyclonal anti-ASC1 antibody (cat no. ab70627), rabbit polyclonal anti-Caspase-1 antibody (pro and cleaved cat no. ab207802), rabbit polyclonal antiCaspase-1 antibody (cleaved and IF cat no. 1872), Rabbit monoclonal anti-GSDMD antibody (cat no. ab209845), Alexa Fluor ${ }^{\circledR} 594$ (cat no. ab15008), and rabbit polyclonal anti-Caspase-1 antibody (pro and cleaved cat no. ab207802) were purchased from Abcam (Cambridge,
MA ${ }^{\circledR}$. Rabbit polyclonal anti-IL-18 body (pro and cleaved, H-173): sc-7954 (Santa Cruz Biotechnology), and rabbit polyclonal Beta-actin antibody (cat no. 205361-AP) was bought from Proteintech ${ }^{\circledR}$ (Chicago, USA).

\section{Statistical Analysis}

GraphPad Prism ${ }^{\circledR} 6.0$ was used for statistical analysis and graphical representation of data. The one-way ANOVA was used to detected statistical significance with three or more among groups' mean, followed by post hoc Dunnett's $t$-test. The data expressed as mean $\pm \mathrm{SD}$ and $\mathrm{P}<0.05$ are considered to statistically significant.

\section{Results}

\section{Gamma Radiation-Induced Cell Death in Microvascular Endothelial Cells by Flow Cytometry Analysis of Caspase I}

The effect of radiation-induced cell death was elucidated by assessing the active caspase -1 through flow cytometry analysis FAM-FLICA assay kits. As demonstrated in Figure 1A, cells stained with PI $+(\mathrm{Q} 3)$ and cleaved caspase 1 (p20) were found to express (Q1) cells after radiation exposure. Then, those that stained doublepositive, FLICA+, and PI + (Q2) found with elevation radiation exposure exhibit more cleaved caspase -1 and event to pyroptosis death (early apoptosis). Figure 1B and $\mathrm{C}$; illustrate the percentages of cells that underwent cell death for both early and late apoptosis within endothelial cells (Figure $1 \mathrm{~B}$ and $\mathrm{C}, \mathrm{P}<0.05$ and 0.0001 ). However, the post-hoc $t$-test also confirmed gamma radiation-induced endothelial to premature cell death (pyroptosis) except in $2 \mathrm{~Gy}$ and late cell death (apoptosis) irrespective of the dose compared to the control cells (Figure $1 \mathrm{~B}$ and $\mathrm{C}, \mathrm{P}<0.05$, 0.01 and 0.0001 ).

These findings indicated that ionizing radiation could activate caspase- 1 and initiated cell death in microvascular endothelial cells after post-irradiation. Furthermore, this data also suggested that the induction of microvascular endothelial to cell death is unstable in low doses and stable in higher doses.

\section{Gamma Radiation Activates NLRP-I and NLRP-3 Inflammasome in Microvascular Endothelial Cells}

We investigate the inflammasome signaling of endothelial cells by detecting the mRNA and protein expression level 


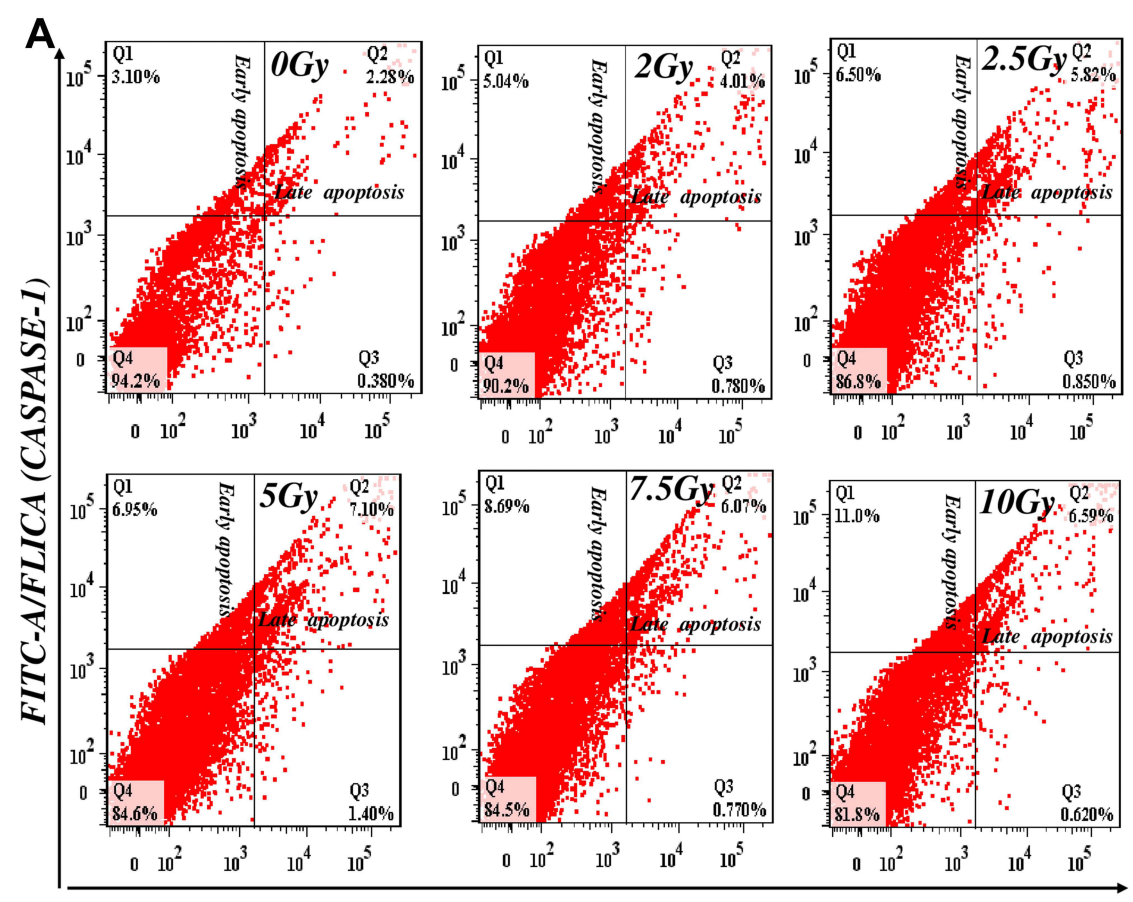

PROPIDIUM IODIDE ( PI)

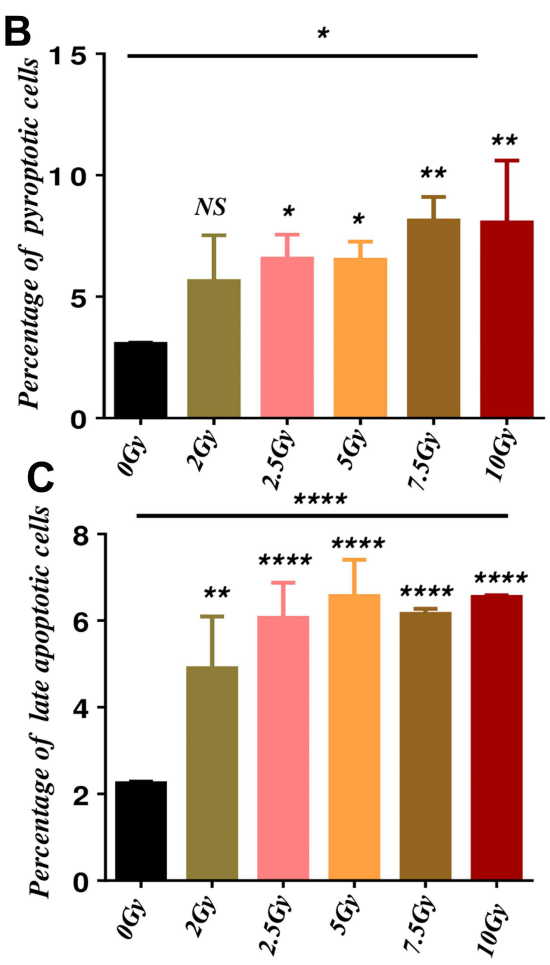

Figure I Gamma radiation-induced cell death in microvascular endothelial cells.

Notes: (A) Assessment of the inflammasome by caspase Assays (FAM-FLICA ${ }^{\circledR}$ ). The cells were classified into four subgroups as shown with the unlabeled space indicates DNA cell fragments and damage. Quantitative analysis of PI + FAM-FLICA flow cytometry analysis (B) percentage of cells that underwent early apoptosis (pyroptosis) and (C) percentage of cells that underwent late apoptotic cells. The results are representative of 6 independent of three experimental repeats $(\mathrm{N}=3)$ (mean $\pm \mathrm{SD}$ ) $* \mathrm{P}<0.05$, $* * \mathrm{P}<0.01$, **** $\mathrm{P}<0.000 \mathrm{I}$ and NS.

Abbreviation: NS, not significant.

after 24 hours of post-irradiation. As described in Figure 2A, the mRNA expression of NLRP-1 upregulated in all the coveted doses of ionizing radiation with the lowest in $2 \mathrm{~Gy}$ and the highest in 10Gy, respectively (Figure $2 \mathrm{~A}, \mathrm{P}<0.0001$ ). The post hoc $t$-test also affirmed that ionizing radiation stimulates the NLRP-1 gene in the endothelial cells irrespectively of the dose after exposure (Figure 2A, $\mathrm{P}<0.0001$ ). Furthermore, we elucidated the expression level of NLRP-1 and NLRP -3 proteins in microvascular endothelial cells after 24 hours of post-irradiation by immunoblotting analysis (Figure 2B). As demonstrated in Figure $2 \mathrm{C}$ and $\mathrm{D}$, the relative quantified proteins of NLRP-1 and NLRP3 shown an increase in expression level in microvascular endothelial cells after 24 hours of post-irradiation (Figure $2 \mathrm{C}$ and $\mathrm{D}, \mathrm{P}<0.0001)$. In addition, the post-hoc $t$-test also confirmed gamma radiation activate Nod-like receptor (NLRs) genes of NLRP-1/NLRP-3 in endothelial cells irrespective of the dose of gamma radiation (Figure $2 \mathrm{C}$ and $\mathrm{D}, \mathrm{P}<0.05$, 0.010 .001 , and 0.0001) compared to the control cells. Notably, these findings implied that NLRP-1 and NLRP-
3 mediates by ionizing radiation in endothelial cells and induces inflammasome signaling after post-irradiation.

\section{Gamma Radiation Enhances the Inflammasome Activation of Caspase-I Dependent and Independent Pyroptosis in Microvascular Endothelial Cells}

Therefore, we investigated the expression level of caspase -1 by RT-qPCR and Western blot analysis. As described in Figure 3A, the mRNA expression level of caspase in irradiated endothelial cells significantly increases 24 hours postirradiation (Figure $3 \mathrm{~A}, \mathrm{P}<0.0001$ ). The post hoc $t$-test also affirmed that ionizing radiation stimulates the caspase-1 gene in irradiated endothelial cells with the lowest in 2.5 Gy and highest in 10Gy, respectively, compared to the controls group (Figure $3 \mathrm{~A}, \mathrm{P}<0.0001$ ). Furthermore, we measured the protein expression level of inactive/cleaved caspase-1 by immunoblotting techniques (Figure 3B), revealing a relative up-regulation in the ratio of cleaved caspase 1/pro-caspase-1 in irradiated endothelial cells (Figure 3D, $\mathrm{P}<0.01$ ). Also, the post-hoc $t$-test confirmed 

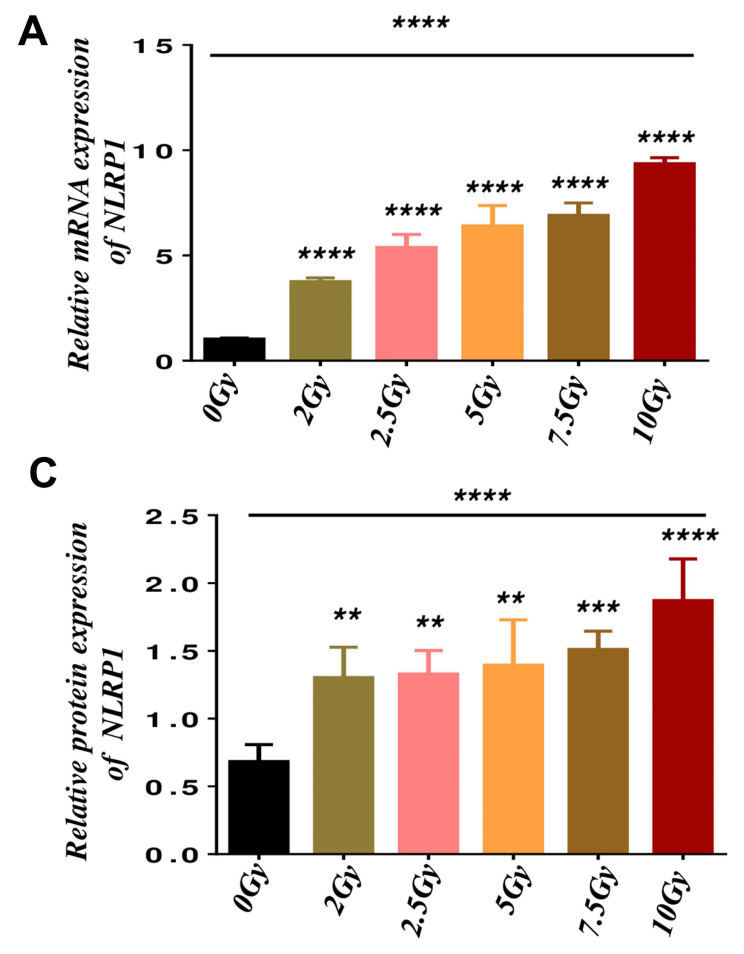

B

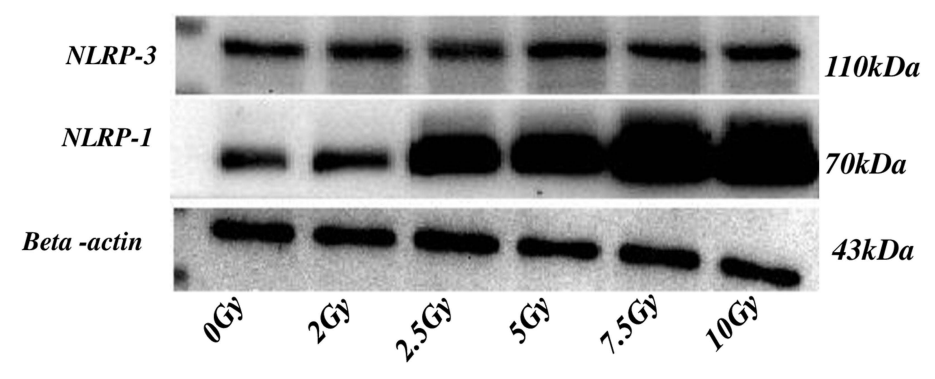

D

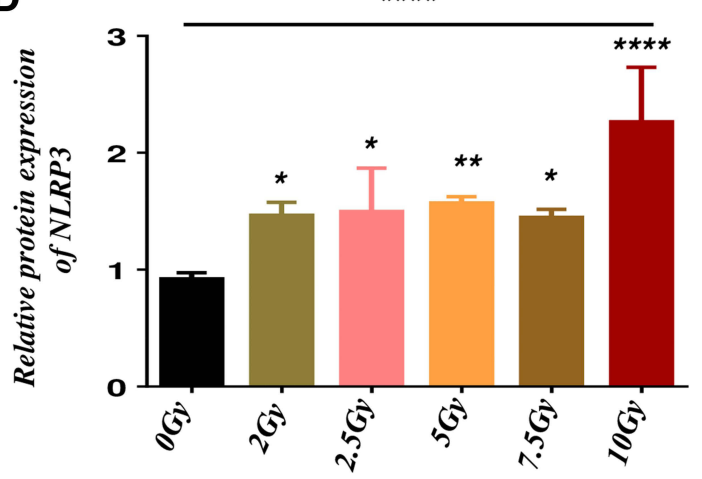

Figure 2 Gamma radiation activates Nod-Like receptors genes of NLRP-I and NLRP-3 inflammasome in microvascular endothelial cells.

Notes: (A) Describe the relative mRNA expression of NRLP-I using glyceraldehyde-3-phosphate dehydrogenase (GAPDH) and beta-actin as endogenous genes (B) Western blotting imaging of NRLP-3, NLRP-I, and Beta-actin related proteins. (C and D) Relative protein expression of NLRP-I and NLRP-3 quantified by Image J software. The results were representative of 6 independent experiments of four repeats $(\mathrm{N}=4)$ (mean $\pm \mathrm{SD}$ ) and target protein normalized by Beta-actin. $* \mathrm{P}<0.05$, $* * \mathrm{P}<0.0 \mathrm{I}$, $* * * \mathrm{P}<0.001$, $* * * * \mathrm{P}<0.0001$.

the activation of cleaved caspase/pro-caspase-1 ratio with the highest in 10Gy and lowest in 5Gy compared to the control cells (Figure 3D, $\mathrm{P}<0.05$ and 0.01 ). We also measure the protein level of ASC-1 by immunoblotting (Figure 3B), which reveals an increase in the expression of ASC-1 protein in irradiated endothelial cells (Figure 3C, $\mathrm{P}<0.01$ ). However, the post hoc $t$-test confirms upregulation of the ASC-1 proteins except in 2.5Gy with the highest in 10Gy and lowest in 5Gy, compared to the control cells (Figure $3 \mathrm{C}, \mathrm{P}<0.05$ and 0.01 ). These results suggested that activation of the NLRs family of NLRP-1 and NLRP-3 recruits the adaptor protein that forms part of the complex along pro-caspase- 1 turns the inactive pro-caspase to bioactive cleaved caspase -1 in endothelial cells after post ionizing radiation exposure. However, this effect is much stable in 10Gy of gamma radiation with relatively unstable in lower doses. We also performed the immunoblotting analysis of gasdermin D protein (Figure 3B), in which the protein expression of gasdermin $\mathrm{D}$ (Figure $3 \mathrm{E}, \mathrm{P}<0.01$ ) is upregulated in irradiated endothelial cells. However, the posthoc $t$-test affirmed that the significant difference is more marked in $7.5 \mathrm{~Gy}$ and $10 \mathrm{~Gy}$, respectively, compared to the control (Figure 3E, $\mathrm{P}<0.05$ and 0.01). These findings demonstrated that caspase- 1 could be independently induced by pyroptosis via activation of gasdermin $\mathrm{D}$ protein by ionizing radiation of endothelial cells after post-irradiation.

\section{Gamma Radiation Promotes the Production of Pro-Inflammatory Cytokines in Microvascular Endothelial Cells}

This study evaluates the output of pro-inflammatory cytokines in endothelial cells after 24 hours of post-irradiation by RT-qPCR and Western blot analysis. As described in Figure 4A and B, the mRNA expression of interleukin-18 (IL-18) and interleukin 1beta (IL-1 $\beta$ ) increased in microvascular endothelial cells after 24 hours of post-radiation (Figure 4A and B, P $<0.0001$ ). However, the post hoc $t$-test confirms an up-regulation of mRNA expression of IL18 (5Gy, 7.5Gy, and 10Gy) and IL- $1 \beta$ in all the irradiated endothelial cells compared to the control cells (Figure 4A and $\mathrm{B}, \mathrm{P}<0.05$ and 0.0001 ). Furthermore, we investigated the protein expression of these pro-inflammatory cytokines by immunoblotting analysis (Figure 4C), which shows an 
A

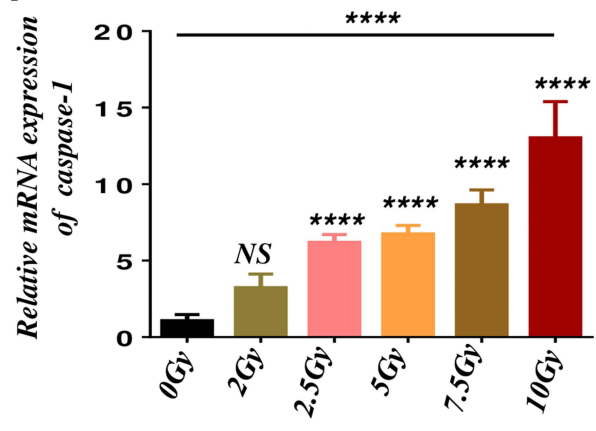

B

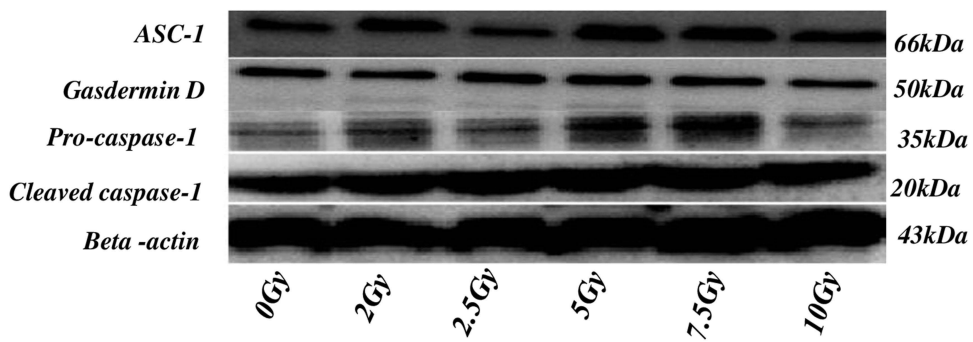

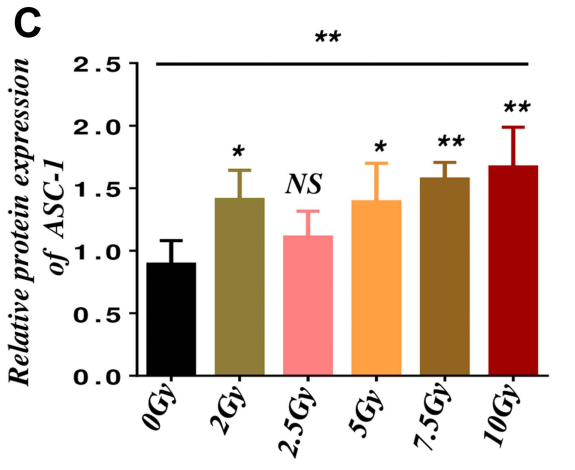
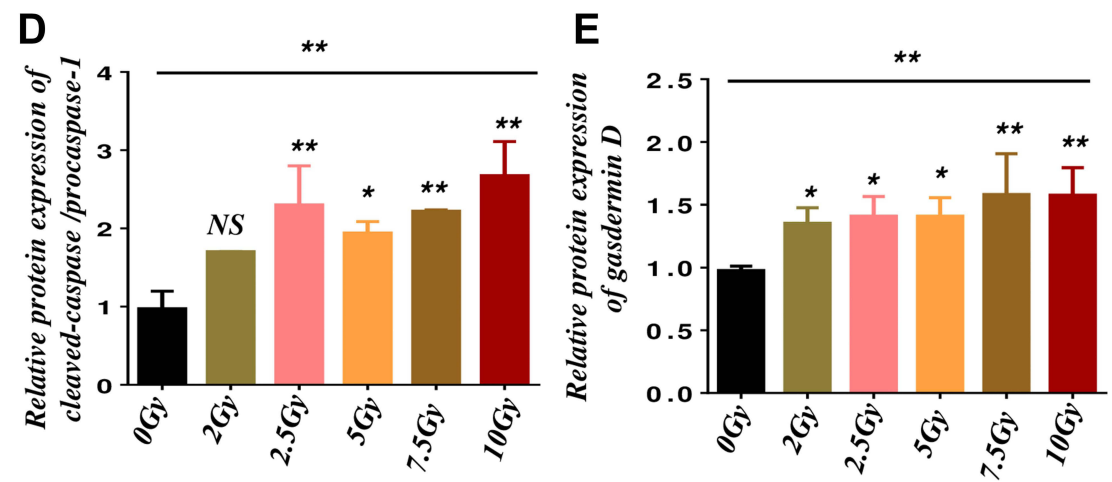

Figure 3 Gamma radiation enhances the inflammasome activation of Caspase-I dependent and independent pyroptosis in microvascular endothelial cells.

Notes: (A) The relative mRNA expression of caspase-I by RT-qPCR using the mean glyceraldehyde-3-phosphate dehydrogenase (GAPDH) and Beta-actin as endogenous normalized genes. (B) Immunoblotting analysis of adaptor molecule apoptosis-associated speck-like proteins (ASC-I) caspase-I, gasdermin D (GSDMD), and beta-actin related proteins. (C-E) The relative protein expression of ASC-I, caspase-I, and GSDMD was quantified by Image J software. The results are representative of 6 independent of four experimental repeats $(\mathrm{N}=4)$ (mean $\pm \mathrm{SD}$ ) using beta-actin as a loading control gene. $* \mathrm{P}<0.05 * * \mathrm{P}<0.0 \mathrm{I}, * * * * \mathrm{P}<0.000 \mathrm{I}$ and $\mathrm{NS}$.

Abbreviation: NS, not significant.

increase in cleaved/pro interleukins (IL-18 and IL-1 $\beta$ ) ratios (Figure 4D and E, $\mathrm{P}<0.01$ and 0.0001). However, the posthoc $t$-test affirms the up-regulation of cleaved/pro interleukin ratio in $5 \mathrm{~Gy}, 7.5 \mathrm{~Gy}$, and $10 \mathrm{~Gy}$ for IL-18, and for IL-1 $\beta$ in $2.5 \mathrm{~Gy}, 5 \mathrm{~Gy}, 7.5 \mathrm{~Gy}$, and $10 \mathrm{~Gy}$ respectively, compared to the control cells (Figure 4D and E, $\mathrm{P}<0.05,0.01$ and 0.0001 ). In addition, it also revealed a down-regulation of IL- $1 \beta$ expression but no significant difference in 2Gy and 2Gy for IL-18. Furthermore, we examined the IL-1 $\beta$ expression by flow cytometry analysis; as described in Supplementary Figure $\underline{\mathrm{S} 1 \mathrm{~A} \text { and } \mathrm{B}}$, the expression of IL-1 $\beta$ was up-regulated in all the coveted doses of gamma radiation in a dose-dependent manner (Figure 1B, $\mathrm{P}<0.01$ ). Furthermore, the post hoc $t$-test shows the up-regulation of the IL- $1 \beta$ expression in (5Gy, $7.5 \mathrm{~Gy}$ and10Gy) compared to the control cells, respectively (Figure S1B $, \mathrm{P}<0.05,0.01$ and 0.001). These findings supported that gamma radiation increase in production of these pro-inflammatory parameters at the site of injury after post-irradiation may potentiate radiation toxicity of endothelial cells and, in turn, impaired their proliferation, regeneration, and remodeling functions.

\section{Gamma Radiation Mediates the Production of HMGB-I and TNF- $\alpha$ in Microvascular Endothelial Cells}

This study determined changes in the expression of highmobility group protein-1(HMGB-1) and tumor necrosis factor-alpha (TNF- $\alpha)$ in endothelial cells after 24 hours post-irradiation by RT-qPCR and Western blotting techniques. As illustrated in Figure 5A, the mRNA expression of HMGB-1 increased in microvascular endothelial cells after post-irradiation (Figure 5A, $\mathrm{P}<0.01$ ). However, the post-hoc $t$-test confirmed that the effect is much higher in $5 \mathrm{~Gy}$, $7.5 \mathrm{~Gy}$, and 10Gy, respectively, than the control (Figure 5A, $\mathrm{P}<0.05,0.01$ and 0.001). We also performed an immunoblotting analysis (Figure $5 \mathrm{C}$ ), which revealed an elevation of the protein expression of HMGB-1 in irradiated endothelial cells (Figure 5E, $\mathrm{P}<0.0001$ ). However, the post hoc $t$-test affirms the significant changes for relative protein expression of HMGB-1 in irradiated endothelial cells compared to the control cells (Figure 5D, $\mathrm{P}<0.01,0.001$ and 0.001). Furthermore, we elucidated the expression level of 

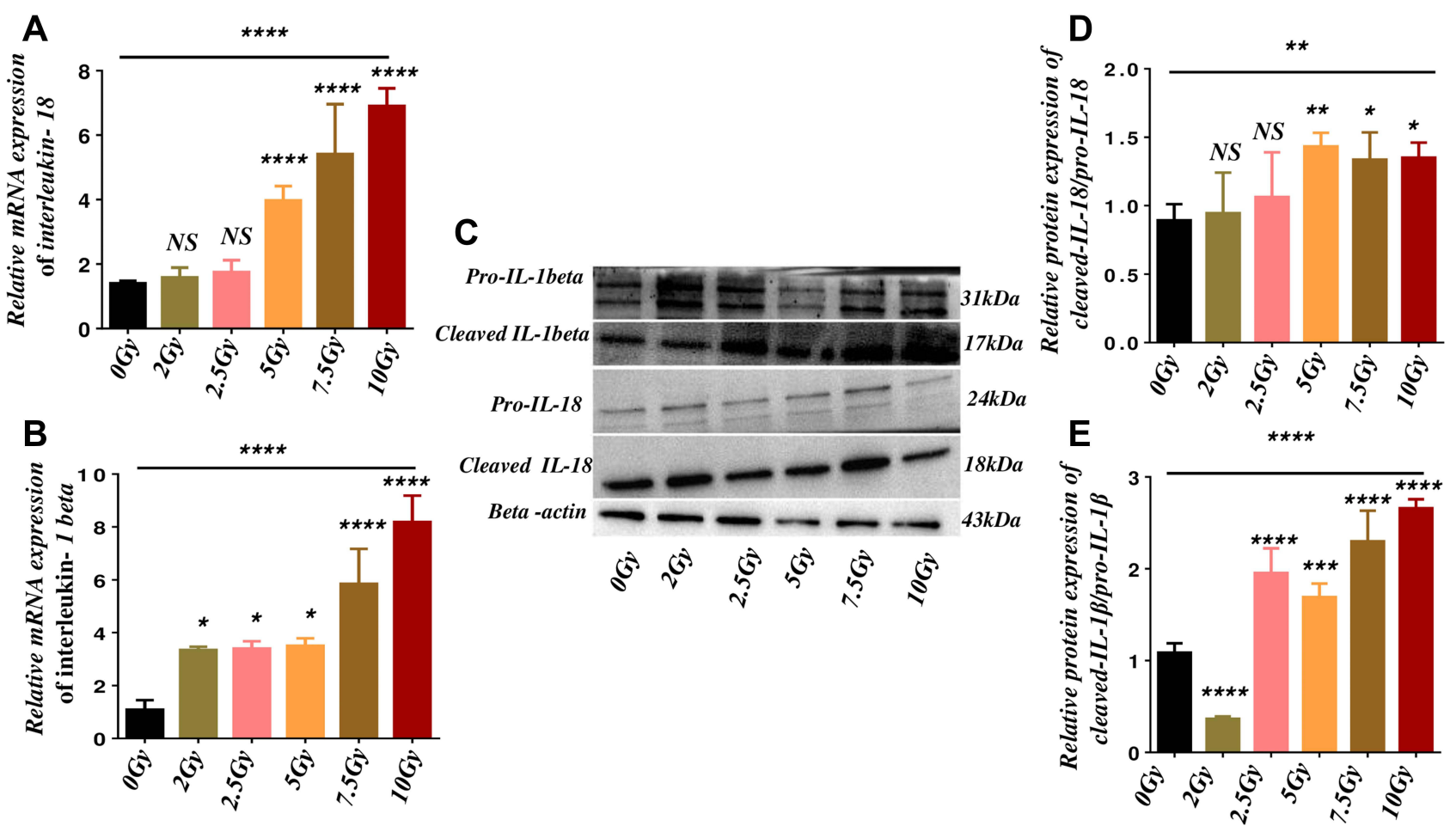

Figure 4 Gamma radiation promotes the production of pro-inflammatory cytokines.

Notes: (A and B) The relative mRNA expression of IL-I8 and IL-I $\beta$, respectively, using the mean of beta-actin and glyceraldehyde-3-phosphate Dehydrogenase (GAPDH) as normalized reference genes. (C) Western blot analysis of pro-inflammatory s cytokines proteins of pro and cleaved interleukin IL-I $\beta$, IL-I8, and beta-actin related proteins. (D and E) The relative protein expression ratio cleaved to pro-IL- 18 and IL-I $\beta$ respectively was quantified with the values of beta-actin by image $\mathrm{J}$ software. The results are representative of 6 independent experiments of four repeats $(\mathrm{N}=4)$ (Mean $\pm \mathrm{SD}$ ) $* \mathrm{P}<0.05, * * \mathrm{P}<0.0 \mathrm{I}, * * * \mathrm{P}<0.00 \mathrm{I}, * * * * \mathrm{P}<0.000 \mathrm{I}$ and $\mathrm{NS}$.

Abbreviation: NS, not significant.

TNF- $\alpha$ microvascular endothelial cells after 24 hours of post-irradiation. As demonstrated in Figure 5B, the mRNA expression of TNFa increased in 5Gy, 7.5Gy, and 10Gy compared to the control cells (Figure 5B, $\mathrm{P}<0.01$ and 0.001). Also, the immunoblotting analysis (Figure 5C) revealed an elevation in the ratio of cleaved TNF- $\alpha /$ proTNF- $\alpha$ except in 2.5Gy (Figure 5E, $\mathrm{P}<0.01$ ). Furthermore, the post-hoc-test shows significant changes in the relative protein expression ratio of cleaved to pro- TNF- $\alpha$ except in 2.5Gy compared to the control (Figure 5E, $\mathrm{P}<0.05$ and 0.01). Overall, these findings supported that HMGB-1 and TNF- $\alpha$ are chemokines produced by radiation-induced death cells in microvascular endothelial cells after postirradiation.

\section{Gamma Radiation Directly Activates Caspase-I Dependent Pathway in Microvascular Endothelial Cells}

To identify the functional role of gamma radiation activation of cleaved caspase-1 in microvascular endothelial cells in post-radiation injury, we investigated the expression level of cleaved caspase-1 by immunofluorescence staining. As shown in Figure 6A and $\mathrm{B}$, the expression level of cleaved caspase 1 in endothelial cells significantly increases in 5Gy, 7.5Gy, and 10Gy, respectively (Figure $6 \mathrm{~B}, \mathrm{P}<0.0001$ ). Furthermore, the post hoc $t$-test shows the up-regulation of the cleaved caspase-1 expression in (5Gy, 7.5Gy and10Gy) compared to the control cells, respectively (Figure 6B, $\mathrm{P}<0.05,0.01$ and 0.001). These findings indicate that gamma radiation can directly activate caspase-1, which in turn potentiates the production of pro-inflammatory cytokines and mediates cell death in microvascular endothelial cells.

\section{Discussion}

Radiotherapy is the rising therapeutic scheme in the management of malignancies that failed to respond to chemotherapeutic agents. As the principal goal of the treatment is to destroy tumor cells and prevent their growth. However, due to ionizing radiation in killing 

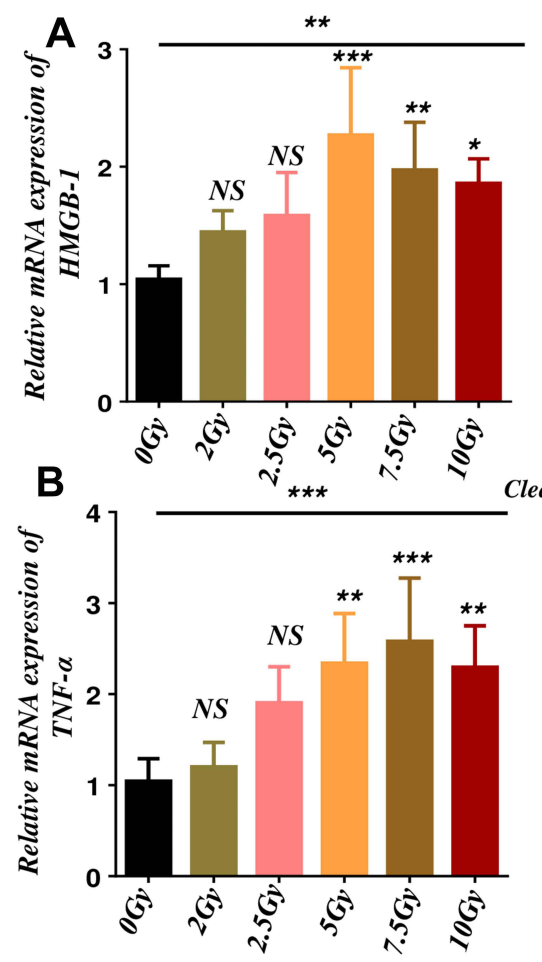
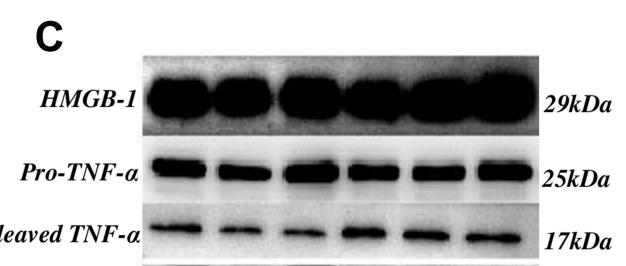

Beta - actin

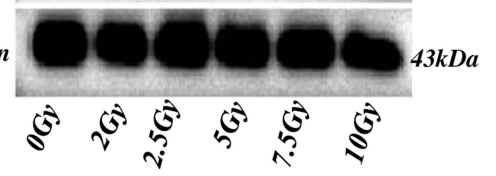

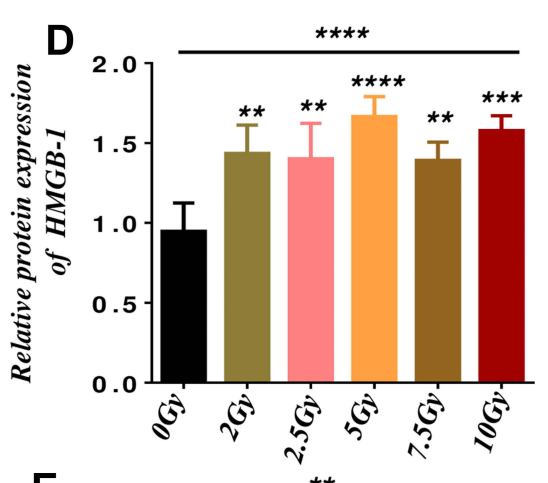

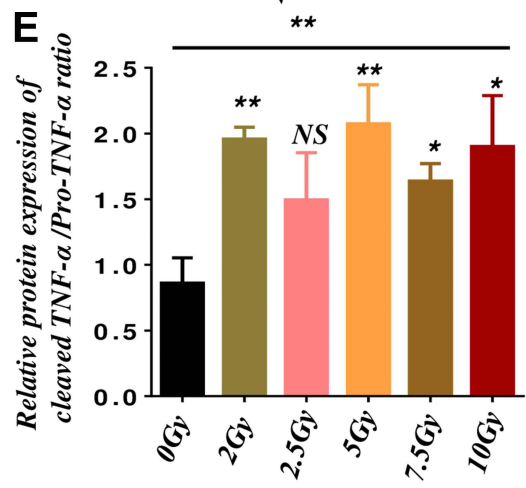

Figure 5 Gamma radiation mediates the production of high-mobility group protein-I (HMGB-I) and tumor necrosis factor-alpha (TNF- $\alpha$ ) in microvascular endothelial cells. Notes: (A and B) Describe the relative mRNA expression of HMGB-I and TNF- $\alpha$ using glyceraldehyde-3-phosphate Dehydrogenase (GAPDH) and beta-actin as reference genes. (C) Western blotting analysis of TNF- $\alpha$, HMGB-I, and Beta-actin related proteins. (D and E) relative protein expression of HMGB-I and TNF- $\alpha$ quantified by Image $\mathrm{J}$ software. The results were representative of 6 independent experiments of four repeats $(\mathrm{N}=4)$ (mean $\pm \mathrm{SD}$ ) and target protein normalized by beta-actin. $* \mathrm{P}<0.05 * * \mathrm{P}<0.0 \mathrm{I}$, $* * * \mathrm{P}<0.00 \mathrm{I}$, $* * * * \mathrm{P}<0.000 \mathrm{I}$, and NS.

Abbreviation: NS, not significant.

only cancer cells, but also damages normal tissues such as the microvascular endothelial cells in the vessels. This may result in the re-occurrence of tumor cells, induced inflammasome signaling, and cell death within the vascular niche of the endothelial cells. Nevertheless, these radiotoxic effects may reduce the quality of a patient's life. ${ }^{3,16-18}$ Therefore, looking at the response of microvascular endothelial cells to ionizing radiation may help build up the therapeutic ratio of cancer radiotherapy and enhance the regeneration of healthy tissues. This study evaluated the gamma radiation-induced cells in microvascular endothelial cells by using the caspase Assays (FAM-FLICA $^{\circledR}$. Our results show that gamma radiation invokes cell damage and even cell death; firstly, we observed that ionizing radiation induction of microvascular endothelial cells in lower doses of gamma radiation is unstable. Secondly, we saw an increase in the percentage of both pyroptosis and apoptosis in higher doses $(\geq 7.5 \mathrm{~Gy})$. Based on these results, it is confirmed that caspase- 1 activation is connected to cell death immediately after radiation exposure. We further investigated whether ionizing radiation can activate the inflammasome signaling in the microvascular endothelial cells. We tested the mRNA and protein expression of NRLP 1, which contains the nucleotide-binding domain (NBD) and leucine-rich repeat (LRR)-containing proteins. Our data proves that ionizing can triggers the arms of the NLRP-1 complex by increasing the expression of both mRNA and proteins in microvascular endothelial cells.

Nonetheless, we sought to examine the protein expression of NLRP-3, which revealed a similar expression to that of NLRP-1. Besides, our findings also suggested that the NLRP1/NLRP-3 genes activated in endothelial cells after radiation exposure. Our results align with many publications that ionizing radiation can stimulate the inflammasome pathway in various types of cells that play a role in the innate immune system. ${ }^{19-23}$ Moreover, since NLR-family inflammasome consists of multi-complex such as adaptor protein (ASC), caspase-1, and caspase -6 that acts as a sensor for DAMPs induced by ionizing radiation. We assessed the protein expression of this adaptor protein (ASC-1) and cleaved caspase-1, were both revealed an increment in expression after radiation. However, this effect is much stable in high doses of ionizing radiation with relatively 


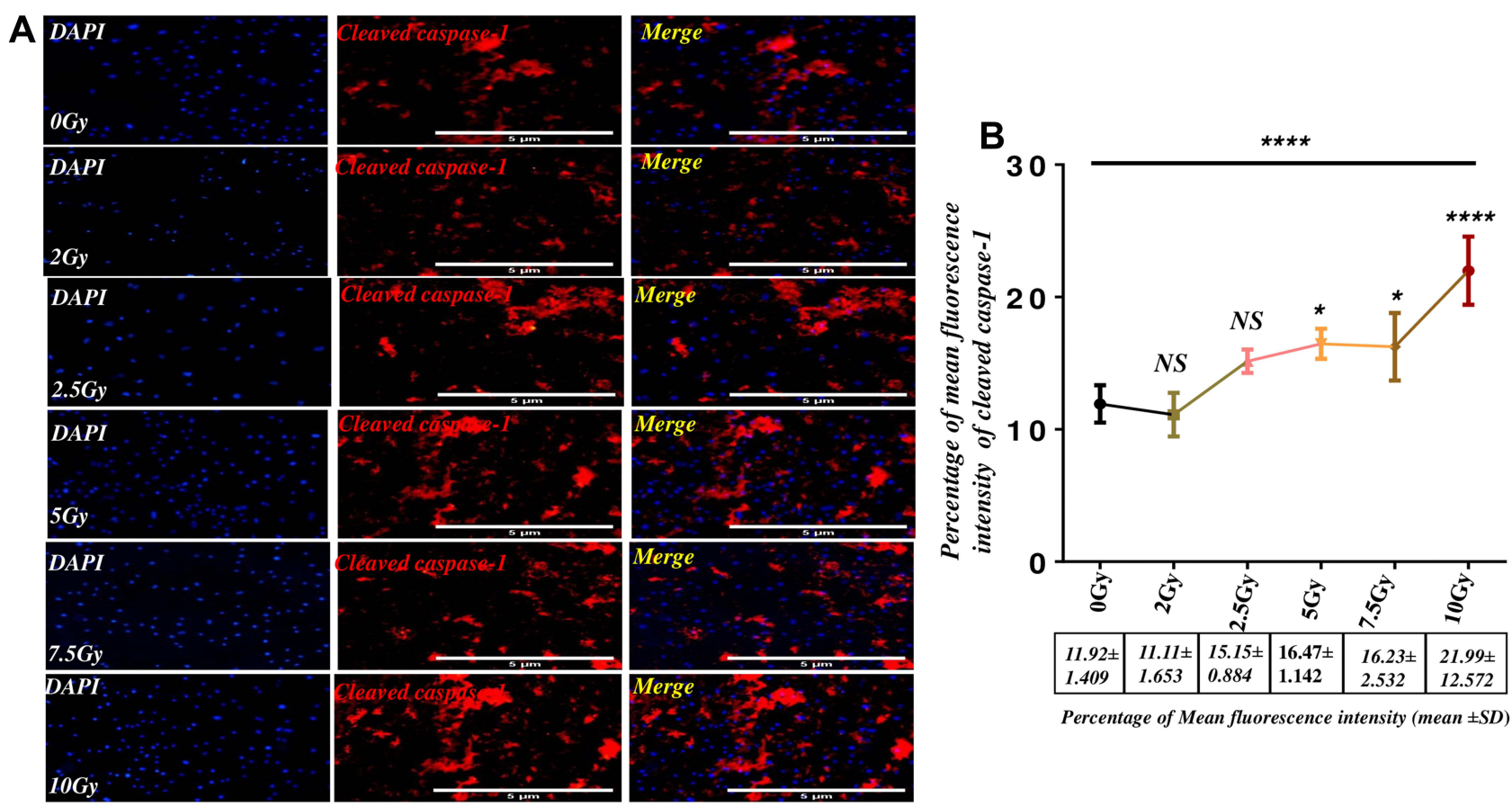

Microvascular endothelial cells (MECs)

Figure 6 Gamma radiation directly activates Caspase-I dependent pathway in microvascular endothelial cells.

Notes: (A) Immunofluorescence images of cleaved caspase -1 in microvascular endothelial cells. (B) The mean fluorescence intensity of cleaved caspase -1 in microvascular endothelial cells in the graph was relatively quantified by image J, which shows a dose-dependent increase in the expression of cleaved caspase-I. The results were representative of 6 independent experiments of four repeats $(N=4)$ (mean $\pm S D$ ) $* P<0.05, * * * * P<0.000$ I and NS.

Abbreviation: NS, not significant.

unstable lower doses of gamma radiation in microvascular endothelial cells. Our results favor the hypothesis that this multi-complex senses the DAMPs induced by radiation injury that recruits caspase recruitment domain (CARD)containing the procaspase- 1 indirectly or via the interposition of CARD-containing ASC. However, activation of the inflammasome complexes stimulates cleaved caspase-1, which independently enhances the maturation and release of pro-inflammatory cytokines such as IL-1 $\beta$ and IL-18 and cell death pyroptosis, releasing other pro-inflammatory cytokines as TNF- $\alpha$ and HMBG-1. Besides, these findings suggested that gamma radiation enhances the production of these cytokines after post-irradiation.

Nevertheless, our data are in line with the above hypotheses mechanisms supported by other corresponding studies. However, our findings also agreed with several studies that ionizing radiation-induced cell death called pyroptosis potentiates the release of HMGB-1 and TNF- $\alpha$. Furthermore, other similar related studies support our findings that activation of NLRs initiates the release of IL-1 $\beta$ and IL-18 via the caspase-1 signaling and mediates the release of other cytokines, which contributes to inflammatory process influences by radiation and thus dispense to the unpleasant effect of radiation. Also, caspase-1 can be actuated dependently, auto-cleaved to mature caspase -1 , and turn on the gasdermin D protein, a substrate of caspase -1 that perforates the plasma membrane of the cells to invoke cell swelling and osmotic lysis that event to cell death. ${ }^{22,24-}$ 27 Thus these findings are braced by other interrelated studies, as illustrated in Figure 7.

\section{Conclusion}

These findings suggested that reducing the unfavorable effect of radiation injury could be challenging. Furthermore, gamma radiation induces the microvascular endothelial cells to cell death activates the inflammasome signaling via different pathways. Therefore, more research needs to be done to address the concept of microvascular endothelial cells associated with inflammasome complexes that mediate the release of proinflammatory cytokines and chemokines release after cell death all contribute to the unwanted toxicity of radiation in the management of cancers. 


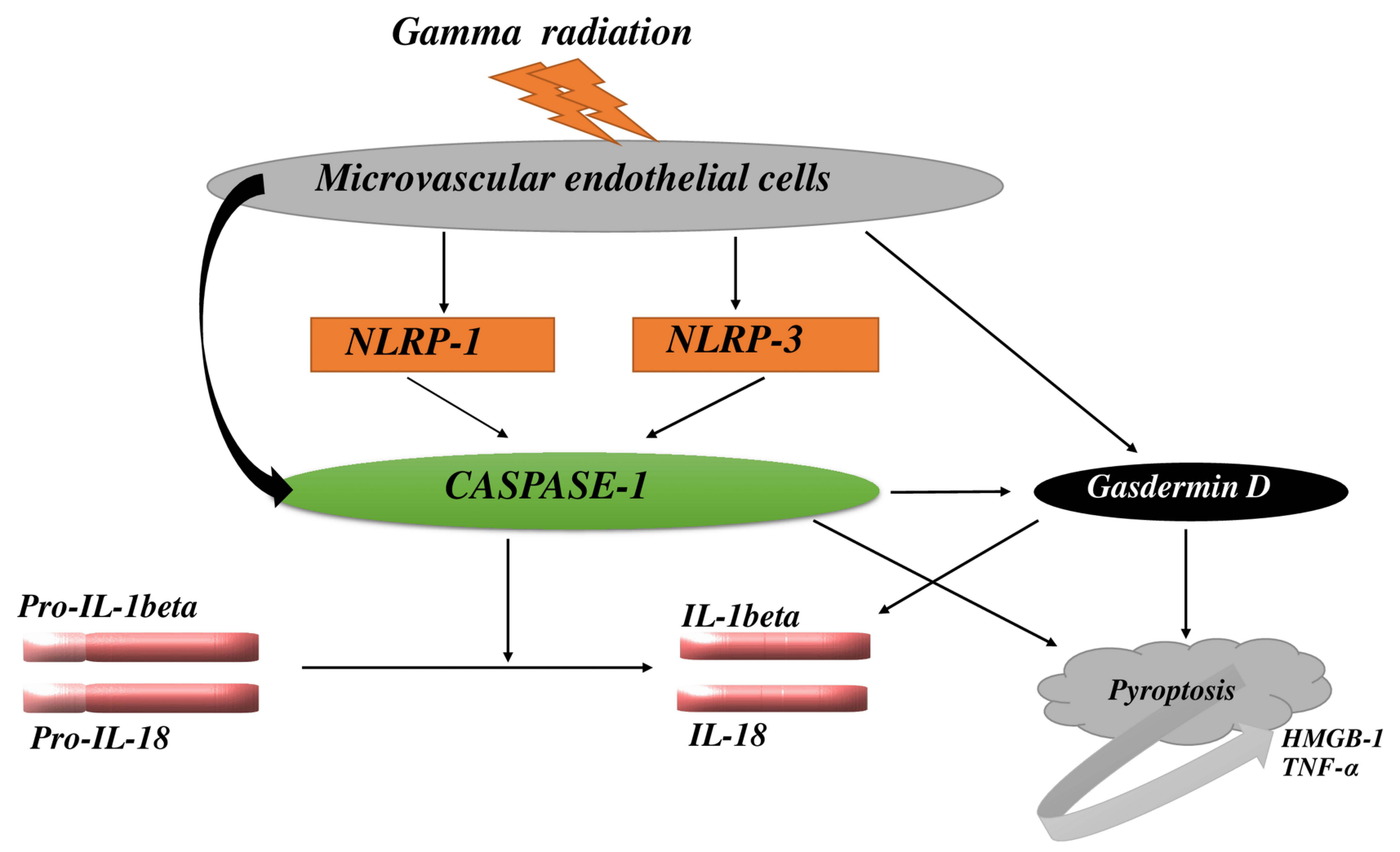

Figure 7 Schematic representation of Nod-like receptor (NLR) of NLRPI/NLRP3 inflammasome in microvascular endothelial cells.

Notes: Gamma radiation activates microvascular endothelial cells via multiple pathways that mediate the cell death and production of pro-inflammatory cytokines (IL-I $\beta$ and IL-I8) and chemokines; high-mobility group protein-I (HMGB-I) and tumor necrosis factor-alpha (TNF- $\alpha$ ).

\section{Data Sharing Statement}

All relevant data in the study are included in the article; further inquiries can be directed to the corresponding authors.

\section{Acknowledgment}

The authors would like to acknowledge the contribution, support, and expert advice of the corresponding authors.

\section{Author Contributions}

All authors made a significant contribution to the work reported, whether that is in the conception, study design, execution, acquisition of data, analysis and interpretation, or in all these areas; took part in drafting, revising or critically reviewing the article; gave final approval of the version to be published; have agreed on the journal to which the article has been submitted; and agree to be accountable for all aspects of the work.

\section{Funding}

This study was supported by the National Natural Science Foundation of China [Grant number 31872795, 81570096 and 81700178]; Major Basic Research Project of the Natural Science[Grant number 17KJA320008]; Jiangsu Provincial Key Research and Development Program [Grant number BE2018637]; Jiangsu Province's Key Provincial Talents Program under Grant [number ZDRCA2016054]; Foundation of the Jiangsu Higher Education Institutions Natural Science Foundation of Jiangsu Province under Grant [number BK20170259]; China Postdoctoral Science Foundation Grant [number 2018M632380]; and Jiangsu Postdoctoral Science Foundation under Grant [number 1701064B].

\section{Disclosure}

The authors declared that there is no conflicts of interest in this research article.

\section{References}

1. Himburg HA, Sasine J, Yan X, Kan J, Dressman H, Chute JP. A molecular profile of the endothelial cell response to ionizing radiation. Radiat Res. 2016;186(2):141. doi:10.1667/RR14444.1

2. Kim SD, Yi JM, Park MT. Irradiated endothelial cells modulate the malignancy of liver cancer cells. Oncol Lett. 2019;17(2):2187-96. doi:10.3892/ol.2018.9833 
3. Baskar R, Dai J, Wenlong N, Yeo R, Yeoh KW. Biological response of cancer cells to radiation treatment. Front Mol Biosci. 2014;1:24. doi:10.3389/fmolb.2014.00024.

4. Baskar R, Lee KA, Yeo R, Yeoh KW. Cancer and radiation therapy: current advances and future directions. Int J Med Sci. 2012;9 (3):193-199. doi:10.7150/ijms.3635

5. Borrego-Soto G, Ortiz-López R, Rojas-Martínez A. Ionizing radiation-induced DNA injury and damage detection in patients with breast cancer. Genet Mol Biol. 2015;38(4):420-432. doi:10.1590/S1415-475738420150019

6. Rodriguez E, Chevalier J, El Ghoul H, Voldum-Clausen K, Mundy J, Petersen M. DNA damage as a consequence of NLR activation. PLoS Genet. 2018;14(2):e1007235. doi:10.1371/journal.pgen.1007235

7. Madeline Lederer LR, Wanke-Jellinek L, Veit M Stoecklein JA, et al. Pathway activation in immune cells radiation exposure induces inflammasome radiation exposure induces inflammasome pathway activation in immune cells. $J$ Immunol. 2018. doi:10.4049/ jimmunol.1303051

8. West CM, Barnett GC. Genetics and genomics of radiotherapy toxicity: towards prediction. Genome Med. 2011;3(8):52. doi:10.1186/ gm 268

9. Gaidt MM, Hornung V. Pore formation by GSDMD is the effector mechanism of pyroptosis. EMBO J. 2016;35(20):2167-2169. doi:10.15252/embj.201695415

10. Zhou H, Jin C, Cui L, et al. HMGB1 contributes to the irradiation-induced endothelial barrier injury through receptor for advanced glycation endproducts (RAGE). J Cell Physiol. 2018;233 (9):6714-21. doi:10.1002/jcp.26341

11. Schroder K, Tschopp J. The inflammasomes. Cell. 2010;140 (6):821-832. doi:10.1016/j.cell.2010.01.040

12. Lu B, Wang H, Andersson U, Tracey KJ. Regulation of HMGB1 release by inflammasomes. Protein Cell. 2013;4(3):163-167. doi:10.1007/s13238-012-2118-2

13. Rajendran P, Rengarajan $\mathrm{T}$, Thangavel J, et al. The vascular endothelium and human diseases. Int J Biol Sci. 2013;9(10):1057-1069. doi:10.7150/ijbs. 7502

14. Michiels C. Endothelial cell functions. J Cell Physiol. 2003;196 (3):430-443. doi:10.1002/jcp.10333

15. Medici D, Shore EM, Lounev VY, Kaplan FS, Kalluri R, Olsen BR. Conversion of vascular endothelial cells into multipotent stem-like cells. Nat Med. 2010;16(12):1400-1406. doi:10.1038/nm.2252
16. Lomax ME, Folkes LK, O'Neill P. Biological consequences of radiation-induced DNA damage: relevance to radiotherapy. Clin Oncol. 2013;25(10):578-585. doi:10.1016/j.clon.2013.06.007

17. Tsai SR, Hamblin MR. Biological effects and medical applications of infrared radiation. J Photochem Photobiol B Biol. 2017;170:197-207. doi:10.1016/j.jphotobiol.2017.04.014

18. Verma N, Tiku AB. Significance and nature of bystander responses induced by various agents. Mutat Res Rev Mutat Res. 2017;773:104-121. doi:10.1016/j.mrrev.2017.05.003

19. Sand J, Fenini G, Grossi S, et al. The NLRP1 inflammasome pathway is silenced in cutaneous squamous cell carcinoma. J Invest Dermatol. 2019;139(8):1788-1797.e6. doi:10.1016/j.jid.2019.01.025

20. Zhai Z, Liu W, Kaur M, et al. NLRP1 promotes tumor growth by enhancing inflammasome activation and suppressing apoptosis in metastatic melanoma. Oncogene. 2017;36(27):3820-3830. doi:10.1038/onc.2017.26

21. Zhai Z, Liu W, Luo Y, et al. 647 NLRP1 promotes tumor growth by enhancing inflammasome activation and suppressing caspase-3 activity in human melanoma. J Invest Dermatol. 2016;136(5):S114. doi:10.1016/j.jid.2016.02.688

22. Zhiyu W, Wang N, Wang Q, et al. The inflammasome: an emerging therapeutic oncotarget for cancer prevention. Oncotarget. 2016;7 (31):50766-50780. doi:10.18632/oncotarget.9391

23. Lebeaupin C, Proics E, De Bieville CHD, et al. ER stress induces NLRP3 inflammasome activation and hepatocyte death. Cell Death Dis. 2015;6(9):e1879-e1879. doi:10.1038/cddis.2015.248

24. Maier P, Hartmann L, Wenz F, Herskind C. Cellular pathways in response to ionizing radiation and their targetability for tumor radiosensitization. Int $J$ Mol Sci. 2016;17(1):102. doi:10.3390/ ijms 17010102

25. Blyth BJ, Cole AJ, MacManus MP, Martin OA. Radiation therapy-induced metastasis: radiobiology and clinical implications. Clin Exp Metastasis. 2018;35(4):223-236. doi:10.1007/s10585-0179867-5

26. Tsuchiya K, Nakajima S, Hosojima S, et al. Caspase-1 initiates apoptosis in the absence of gasdermin D. Nat Commun. 2019;10 (1):1-9. doi:10.1038/s41467-019-09753-2

27. Jia C, Zhang J, Chen $\mathrm{H}$, et al. Endothelial cell pyroptosis plays an important role in Kawasaki disease via HMGB1/RAGE/cathespin B signaling pathway and NLRP3 inflammasome activation. Cell Death Dis. 2019;10(10):1-6. doi:10.1038/s41419-019-2021-3
Journal of Inflammation Research

\section{Publish your work in this journal}

The Journal of Inflammation Research is an international, peerreviewed open-access journal that welcomes laboratory and clinical findings on the molecular basis, cell biology and pharmacology of inflammation including original research, reviews, symposium reports, hypothesis formation and commentaries on: acute/chronic inflammation; mediators of inflammation; cellular processes; molecular mechanisms; pharmacology and novel anti-inflammatory drugs; clinical conditions involving inflammation. The manuscript management system is completely online and includes a very quick and fair peerreview system. Visit http://www.dovepress.com/testimonials.php to read real quotes from published authors. 